\title{
Soluble Interleukin-2 Receptor in Exhaled Breath Condensate in Pulmonary Sarcoidosis: A Cross-sectional Pilot Study
}

Dayle L. Terrington ${ }^{1,2}$, Jee Whang Kim ${ }^{1,2}$, Garth Ravenhill2 ${ }^{2}$, Jonathan Tang ${ }^{1}$, Isabelle Piec ${ }^{1}$, Stephen J. Fowler ${ }^{3}$, William Fraser ${ }^{1,2}$, Andrew M. Wilson ${ }^{1,2}$

\section{Affiliations:}

${ }^{1}$ Norwich Medical School, The University of East Anglia, Norwich, United Kingdom.

${ }^{2}$ Norfolk and Norwich University Hospital NHS Foundation Trust, Norwich, United Kingdom.

${ }^{3}$ Division of Infection, Immunity and Respiratory Medicine, School of Biological Sciences, The University of Manchester; Manchester Academic Health Science Centre and NIHR Manchester Biomedical Research Centre, Manchester University Hospitals NHS Foundation Trust, Manchester United Kingdom.

\section{Contact for Correspondence:}

Dr Dayle Terrington

Clinical Research Fellow in Respiratory Medicine

Bob Champion Research and Education Building

Norwich Medical School

University of East Anglia

Norwich

NR4 7UQ

Telephone: 01603593294

Email: $\quad$ D.terrington@uea.ac.uk

Key words: Sarcoidosis, exhaled breath condensate, breath biomarker, soluble interleukin-2 receptor

\section{Abstract}


Introduction: Sarcoidosis is a chronic granulomatous disease of unknown aetiology with a variable clinical course and prognosis. There is an urgent need to identify new and novel biomarkers to help differentiate between clinical phenotypes and guide clinical decisions with respect to commencing and monitoring treatment. Across the spectrum of respiratory disease there has been a growing interest in the role of breath-based biomarkers given their non-invasive nature and ability to repeat sampling with ease for serial monitoring. Soluble interleukin-2 receptor (sIL2R) in bronchoalveolar lavage and serum correlates with disease activity in sarcoidosis, however no previous study has evaluated SIL2R in exhaled breath. Objectives: The main aim of this cross-sectional case-controlled pilot study was to determine the concentration of sIL2R in exhaled breath condensate (EBC) from patients with recently diagnosed sarcoidosis compared to healthy volunteers and to establish, if present, if this correlated with markers of disease activity, pulmonary function tests and serological markers used in current clinical practice. Methods: Paired serum and EBC samples were collected from twelve treatment naïve patients with histologically proven sarcoidosis diagnosed during the previous six months and compared to twelve healthy volunteers matched for age and gender. Results: Mean concentration of serum SIL2R was significantly elevated in participants with sarcoidosis compared to healthy controls (1584.3 \pm 489.1 versus $874.2 \pm 235.7 \mathrm{pg} / \mathrm{mL} ; \mathrm{p}=0.001$ ). Soluble interleukin-2 receptor in $\mathrm{EBC}$ was detectable in only five subjects including three participants with sarcoidosis. The range of sIL2R across all five samples was $148.0-288.2 \mathrm{pg} / \mathrm{mL}$ with the two highest concentrations observed in two participants with sarcoidosis. There was no significant difference observed in EBC sIL2R between sarcoidosis and healthy controls $(p=0.71)$. No apparent correlations were observed between EBC SIL2R and radiological stage, pulmonary function tests or serological markers. Conclusion: Soluble interleukin-2 receptor is detectable in EBC, however the findings from our study do not support its role as a diagnostic marker in sarcoidosis. Further research is required to evaluate its prognostic utility. 


\section{Background}

Sarcoidosis is chronic multi-system disease of unknown aetiology characterised by the presence of non-caseating epithelioid granulomata (1). Any organ can be affected, however involvement of the lungs and intrathoracic lymph nodes occurs in up to ninety percent of patients (2). Whilst the exact aetiology remains unknown it is thought to arise as a result of an exaggerated immune response to a so-far unidentified antigen in a genetically predisposed individual (3). The clinical course and prognosis of sarcoidosis is extremely variable with spontaneous remission occurring in up to half of patients within two years (3). Up to a third may develop chronic progressive disease associated with increased morbidity and mortality due to pulmonary fibrosis, cardiac or neurological involvement (1). The evidence for currently available biomarkers in determining prognosis and predicting patterns of clinical behaviour is disappointing with most lacking sufficient sensitivity and specificity (4). Whilst some have shown promise such as chitotriosidase (5) (6), many are not routinely available or involve invasive sampling methods such as bronchoscopy and bronchoalveolar lavage and are therefore unsuitable for serial monitoring in the clinical setting. There is a growing need to identify new and novel non-invasive biomarkers to aid diagnosis, differentiate between clinical phenotypes, identify those at risk of disease progression and monitor response to treatment. More recently there has been a growing interest in breath research in respiratory disease in both the diagnostic and prognostic setting (7). When exhaled breath is condensed on a cold surface the resultant exhaled breath condensate $(E B C)$ provides a non-invasive method for obtaining samples from the respiratory tract (8). Although composed mainly of water vapour EBC contains a small proportion of aerosolised droplets and non-volatile molecules which can then be quantified using a variety of analytical techniques (9). During inflammation and disease states the composition of EBC may be altered therefore providing an alternative source of potential biomarkers in sarcoidosis. Although breath research remains in its infancy in sarcoidosis, several studies have shown promising results in differentiating sarcoidosis from healthy controls using a variety of biomarkers present in EBC. Markers of oxidative stress in EBC including hydrogen peroxide (11) and 8-isoprostane (12) (13) are significantly elevated in sarcoidosis alongside various inflammatory cytokines and markers of granulomatous inflammation including transforming growth factor- $\beta_{1}(14)$, tumour necrosis factor- $\alpha$ (15), 
cysteinyl leukotrienes (16) and neopterin (14) compared to healthy controls. However, none sufficiently differentiated between clinical phenotypes (17).

The interleukin-2 receptor consists of three chains; a $y$ chain (CD132), a $\beta$ chain (CD122) and an $\alpha$ chain (CD25), the latter of which is upregulated by activated T-cells and secreted to form the soluble interleukin-2 receptor (sIL2R) (18). Expression of sIL2R therefore acts as a surrogate marker of T lymphocyte activation (19). In sarcoidosis, several studies have identified elevated SIL2R in serum (20) (21), bronchoalveolar lavage fluid (22) and cerebrospinal fluid (23). Serum levels of sIL2R reflect disease activity (24) (25) (26) (27) and progression (28) (29), as well as being elevated in those with pulmonary infiltrates (21) (30) (31), extra-pulmonary manifestations (32) (31) and correlating with improvements in pulmonary function tests following treatment with methotrexate (33). Furthermore serum sIL2R appears to have greater sensitivity in supporting a diagnosis of sarcoidosis in comparison to serum angiotensin converting enzyme and lysozyme (31). To our knowledge, only one previous study has measured SIL2R in EBC, although patients with sarcoidosis were not included (34). The aims of this pilot study were therefore to determine if sIL2R was present and quantifiable in EBC in patients with newly diagnosed sarcoidosis, and to establish if the concentration correlated with markers of disease activity, pulmonary function tests and serological markers used in clinical practice.

\section{Methods}

\section{Study design and participant recruitment}

This was an observational cross-sectional pilot study involving participants with recently diagnosed sarcoidosis attending the respiratory department at the Norfolk and Norwich University Hospital NHS Foundation Trust. Potential participants were identified by screening interstitial lung disease multidisciplinary team meeting outcomes, outpatient clinic letters and referral lists for patients awaiting either transbronchial lung biopsy or endobronchial ultrasound with transbronchial needle aspiration (EBUS-TBNA) for suspected sarcoidosis. Following diagnosis, potential participants were approached whilst attending routine clinical outpatient appointments. For inclusion, all study subjects were $\geq 18$ years of age with a diagnosis of sarcoidosis established during the preceding six months based upon clinical and radiological criteria and confirmed histologically (1). The exclusion criteria 
included treatment with systemic corticosteroids or immunosuppression during the previous three months, current smokers or ex-smokers having ceased less than six months previously, significant respiratory comorbidity other than sarcoidosis, pregnancy, selfreported lower respiratory tract infection or treatment with antibiotics during the previous six weeks alongside any disease or condition known to elevate SIL2R including tuberculosis, autoimmune diseases or an estimated glomerular filtration rate $<30 \mathrm{~mL} / \mathrm{min} / 1.73 \mathrm{~m}^{2}$.

Healthy volunteers were recruited from hospital outpatient departments and consisted of patients, visitors and staff who were matched for gender and age \pm five years. Prior to enrolment, all healthy volunteers underwent spirometry and had no known history of underlying respiratory or chronic disease and took no regular medication. All were nonsmokers or ex-smokers having ceased smoking more than six months previously and had no history of lower respiratory tract infection during the preceding six weeks.

Ethical approval was granted by Yorkshire and Humber Leeds East Research Ethics Committee (Research and Ethics Committee Reference number 18/YH/0171) and all study subjects provided written informed consent to participate.

All participants attended a single research visit and were asked to provide a sample of exhaled breath condensate and serum sample which were sent for routine clinical analysis and stored for measurement of sIL2R. Spirometry was performed on all healthy volunteers and patients with sarcoidosis if they had not had clinical lung function assessment undertaken within four weeks of the time of enrolment.

\section{Exhaled breath condensate and serum sampling and analysis}

Paired serum and exhaled breath condensate samples were collected from all participants at baseline, and repeated sampling took place within two weeks in four patients with sarcoidosis to assess reproducibility. Exhaled breath condensate was collected in accordance with current clinical guidelines and recommendations using an RTube device (Respiratory Research Inc., Charlottesville, VA, USA) (8) (35). Subjects were asked to perform tidal breathing through the RTube which contained an inner sleeve cooled to -20 degrees centigrade. Sampling took place over 7-10 minutes until approximately $1 \mathrm{~mL}$ of EBC had been collected. During sampling, participants were asked to wear a nose clip and swallow 
excessive saliva to reduce sample contamination. Samples were immediately stored at -80 degrees centigrade until analysis.

Following collection of EBC, venepuncture was immediately performed in all participants and blood centrifuged at $2000 \mathrm{~g}$ for 10 minutes at room temperature. The remaining serum was pipetted and stored at -80 degrees centigrade until analysis. All samples were also sent for routine laboratory analysis including a full blood count, liver function test, C-reactive protein, urea and electrolytes and calcium as part of routine clinical care alongside measurement of the erythrocyte sedimentation rate and serum angiotensin converting enzyme in all twelve participants with sarcoidosis. Soluble interleukin-2 receptor was quantified using a Quantikine enzyme linked immunosorbent assay kit (ELISA) which targeted the alpha receptor chain (IL-2R $\alpha$ ) (R\&D Systems, Minneapolis, USA). Freshly thawed serum samples were analysed in accordance with the manufacturer instructions. EBC samples were diluted 1 in 10 with the assay diluent following the manufacturer's guidance for analysis of biological supernatants. All serum and EBC samples were analysed in duplicate and all laboratory researchers undertaking analysis of samples were blinded to the disease status of participants. The assay imprecision coefficient of variance (CV) was $<15 \%$ across the concentration range from 5.0 to $5000 \mathrm{pg} / \mathrm{mL}$, with a lower limit of detection for the assay of $10 \mathrm{pg} / \mathrm{mL}$. The assay cross-reactivity against a wide range of mediators and cytokines was $<0.5 \%$ (See supplementary data 1 ). The manufacturers referenced mean and standard deviation for sIL2R in the serum of fifty five healthy volunteers was reported as $1055 \pm 365 \mathrm{pg} / \mathrm{mL}$ with a range of $485-1997 \mathrm{pg} / \mathrm{mL}$. Therefore for all serum samples, a value of $1770.4 \mathrm{pg} / \mathrm{mL}$ (two standard deviations above the referenced mean value for healthy controls) was considered the upper limit of normal. No data were available for the referenced ranges in EBC. For all EBC samples in which sIL2R was undetectable, an arbitrary value of half the lower limit of detection was assigned.

\section{Spirometry and pulmonary function tests}

Spirometry, static lung volumes and transfer factor of the lung for carbon monoxide were measured using a CareFusion Jaeger MasterScreen Body/Diffusion System in accordance with the American Thoracic Society and European Respiratory Society guidelines (36) (37) (38). 


\section{Statistical analysis}

Statistical analysis was performed using IBM SPSS Statistics for Macintosh, Version 25.0 (IBM Corp, Armonk, NY, released 2017). Normally distributed data are presented as mean \pm standard deviation whereas the median and range is presented for data which did not follow Gaussian distribution. Comparisons between normally distributed data were performed using unpaired $t$ tests to calculate the difference between means. For nonparametric data, comparisons were calculated using the Mann-Whitney $U$ test. One-way Analysis of Variance (ANOVA) was performed to evaluate differences between radiological stages. The variance homogeneity between radiological stages was assessed with Levene's test. Spearman correlation coefficient was employed to assess for correlations between non-parametric data. A conventional $p$-value of $<0.05$ was considered statistically significant.

\section{Results}

Twenty four participants were recruited; 12 with sarcoidosis (four were sampled on two occasions as above) alongside 12 healthy volunteers. Soluble interleukin-2 receptor was measured in all twenty eight EBC and serum samples. Baseline characteristics are shown in tables 1 and 2. All study subjects were Caucasian and included seven males and five females in the sarcoidosis cohort with a mean age of $53.0 \pm 16.2$ years compared to a mean age of $51.7 \pm 15.3$ years in the healthy controls. There were no statistically significant differences between participants with sarcoidosis and healthy controls in terms of age or spirometry. Sarcoidosis was confirmed histologically in lymph node tissue obtained during EBUS-TBNA in eleven participants and following a cervical lymph node biopsy in the remaining subject. Alternative causes of granulomatous inflammation were excluded in all patients. Due to abnormal appearances of an intrapulmonary nodule in one subject who underwent EBUSTBNA, an open lung biopsy was performed and confirmed non-caseating granulomatous inflammation. Of the twelve participants with sarcoidosis, based upon the Scadding staging criteria (39), four were classified as stage 0 , three were stage I, two were stage II and two stage III respectively. A chest radiograph was not available for one patient. All twelve participants underwent cross-sectional imaging and had evidence of intrathoracic sarcoidosis despite four being graded as stage 0 on the Scadding criteria (See table 3). 
All participants were symptomatic at the time of recruitment with at least one or more cardinal respiratory symptom including dyspnoea, cough, sputum production, wheeze, chest pain or haemoptysis. At the time of recruitment one patient was receiving treatment with steroid eye drops for uveitis, seven self-reported fatigue and six reported generalised arthralgia. One patient had previous uveitis and erythema nodosum which were resolved at the time of enrolment and a further patient was treated for previous uveitis.

Serum angiotensin converting enzyme (ACE) was elevated in four participants with sarcoidosis, however at the time of the study two subjects were treated for hypertension with ACE inhibitors. With the exception of topical steroid eye drops, no patients had received previous treatment with systemic corticosteroids or immunosuppression.

\section{$\underline{\text { Serum SIL2R }}$}

Soluble interleukin-2 receptor was measured and detectable in all study subjects. The mean serum concentration of sIL2R was significantly increased in sarcoidosis compared to healthy controls (1584.3 \pm 489.1 versus $874.2 \pm 235.7 ; p=0.001)$. Soluble interleukin-2 receptor was elevated $>1770.4 \mathrm{pg} / \mathrm{mL}$ in four participants with sarcoidosis. No healthy controls had sIL2R which exceeded $>1770.4 \mathrm{pg} / \mathrm{mL}$. There was no statistically significant difference in serum levels of sIL2R between radiological stages ( $p$-value 0.36$)$.

\section{Exhaled breath condensate sIL2R}

Soluble interleukin-2 receptor was detectable in five EBC samples including three participants with sarcoidosis (ranging from $148.0-288.2 \mathrm{pg} / \mathrm{mL}$ ) and two healthy controls (ranging from 180.0 - $190.4 \mathrm{pg} / \mathrm{mL}$ ). The median concentration for participants with sarcoidosis and healthy controls was $5.0 \mathrm{pg} / \mathrm{mL}$. No significant difference was observed between the two groups with a $p$-value of 0.71 . There was no apparent correlation of EBC SIL2R in relation to radiological stage. Of the three participants with detectable sIL2R, one had stage 0 disease, one had stage I disease and a chest radiograph was not available for the remaining patient, however on cross-sectional imaging all three participants had bilateral hilar and mediastinal lymphadenopathy alongside non-specific pulmonary nodules. Serum ACE was elevated in one participant and normal in another. The remaining participant with detectable EBC sIL2R had suppressed ACE levels due to treatment with an ACE inhibitor for hypertension. There was no apparent correlation between EBC sIL2R and the Medical 
Research Council dyspnoea score, symptoms or pulmonary function test parameters. Two participants self-reported arthralgia and one reported fatigue. Furthermore, no correlation was observed between the concentration of serum and EBC sIL2R ( $\rho=0.075 ; p=0.73)$. No adverse events were reported in any participant during breath sampling.

\section{Reproducibility testing}

In the four participants that undertook repeated blood and EBC sampling to assess reproducibility, three had undetectable EBC sIL2R at baseline and during repeated sampling. The final patient had a sIL2R concentration of $285.8 \mathrm{pg} / \mathrm{mL}$ in EBC at baseline, however sIL2R was not detected in repeated sampling.

\section{Discussion}

This pilot study aimed to determine if sIL2R was detectable in EBC collected from patients with newly diagnosed sarcoidosis using an enzyme-linked immunosorbent assay with a lower limit of detection of $10 \mathrm{pg} / \mathrm{mL}$. Of the twelve participants with sarcoidosis recruited, all were treatment naïve and sIL2R was detectable in EBC in three subjects with a median concentration of $5.0 \mathrm{pg} / \mathrm{mL}$. Soluble interleukin-2 receptor was also detectable in EBC samples collected from two healthy volunteers matched for age and gender with a median concentration of $5.0 \mathrm{pg} / \mathrm{mL}$. Interestingly, both healthy controls were first-degree relatives however, neither had any personal history of respiratory or granulomatous disease. There was also no family history of sarcoidosis. No significant difference was observed between participants with sarcoidosis or controls, nor was there any apparent association or relationship with the radiological stage, pulmonary function test parameters or serological markers of disease activity used in current clinical practice. In contrast, serum sIL2R was detected at significantly higher concentrations in patients with sarcoidosis compared to healthy controls in keeping with previously published research (21). However, no correlation was observed between serum sIL2R and differing radiological stages.

Of the twenty eight EBC samples collected, we were not able to detect or quantify sIL2R in twenty three samples. In those samples where SIL2R was present above the lower limit of detection, the concentration ranged from $148.0-288.2 \mathrm{pg} / \mathrm{mL}$ compared to serum where SIL2R was present at much higher concentrations ranging from $612.5-2689.6 \mathrm{pg} / \mathrm{mL}$ in both participants with sarcoidosis and healthy controls. The principle composition of EBC is 
water vapour (40) with small amounts of water soluble volatile compounds and non-volatile molecules (8). The origin of non-volatile biomarkers within EBC remains unclear and is thought to arise as a result of turbulent airflow across epithelial lining fluid during tidal breathing which leads to aerosolisation of components within the airway lining fluid. Aerosol formation can also be explained by the bronchiole fluid film bursting model whereby aerosols are generated due to the formation of a respiratory fluid film or bubble bursting during inspiration and reopening of bronchioles (10). The concentration of such components in EBC is much lower than that found in airway lining fluid (41). Dilution in EBC therefore renders the concentration of many biomarkers measured using conventional immunoassays either close to or below the lower limit of detection for the assay (9). Moreover, commercial assay kits are not validated for use in EBC analysis (9). The concentration of sIL2R in our study may have been at or below the lower limit of detection resulting in the inability to quantify the protein in EBC samples accounting for our findings and indicating the need to identify more sensitive analytical techniques such as proteomics, metabolomics and mass spectrometry.

Concentrating samples using methods such as lyophilisation have been evaluated to overcome the problems arising due to excessive sample dilution. The resultant freeze-dried sample is then reconstituted in a smaller volume of diluent prior to analysis. Whilst some researchers have described successful methods surrounding lyophilisation in the measurement of 8-isoprostane (42), o-tyrosine (42), proteins (43) and metabolomic analysis (44), other mediators such as cysteinyl leukotrienes undergo variable and unacceptably high degradation following the process of freeze-drying (45). Therefore at present very little is known about the reliability and reproducibility of lyophilisation which has been highlighted in the recent technical standard published by the European Respiratory Society in relation to exhaled biomarkers in lung disease (35). Due to the lack of sufficient evidence surrounding lyophilisation as well as the fact our samples were immediately stored at -80 degrees centigrade, to minimise the effects of sample degradation with repeated freeze-thaw cycles we did not perform repeated analysis using lyophilised samples.

In order to assess the reproducibility of measuring EBC sIL2R, we undertook repeated sampling in a subgroup of four participants with sarcoidosis. During baseline sampling, sIL2R was detectable in one subject however on repeated sampling sIL2R was undetectable. Given 
the fact there was no significant change in self-reported symptoms or serum concentration of sIL2R between the baseline and reproducibility visit, it is unlikely this difference reflects a true biological variation. Baseline sample contamination may account for the differing results obtained and whilst subjects were asked to swallow excessive saliva during sampling, we cannot definitively exclude salivary contamination. Although no previous study has measured the concentration of salivary SIL2R in sarcoidosis, research by Tishler et al identified elevated salivary SIL2R in patients with Sjogren's syndrome compared to undetectable levels in controls (46). However, whilst parotid involvement can rarely occur in sarcoidosis, no participants self-reported symptoms suggestive of sarcoid related parotitis. In addition, although less likely sample contamination may have occurred during the analytical phase. Finally, the lack of intra-subject reproducibility may simply reflect the limitations of using immunoassays and the potential of giving rise to false positive results when measuring biomarkers which fall close to the assays lower limit of detection. To our knowledge only one previous study has sought to measure sIL2R in exhaled condensate in participants with a range of respiratory diseases including asthma, chronic obstructive pulmonary disease, bronchiectasis, pneumonia, interstitial lung disease and lung cancer using an alternative ELISA kit (T-Cell Sciences, Inc., Cambridge, MA) (34). Soluble interleukin2 receptor was detectable in seven out of sixteen subjects and ranged from $8-2159$ units $/ \mathrm{mL}$, however patients with sarcoidosis were not included within the study. Furthermore, in contrast to our study, there was inadequate matching of the study subjects with healthy controls. There was also considerable heterogeneity amongst participants with respiratory disease with many having dual pathologies as well as a lack of control of many potential confounders such as smoking and treatment exposure. In three participants recruited with fibrotic interstitial lung disease, two had undetectable sIL2R in EBC and the remaining participant only had a very low concentration detectable in comparison to alternative patients recruited who predominantly had airway diseases. In sarcoidosis and other interstitial lung disease, the parenchyma and interstitium is predominantly affected as opposed to the airway. Therefore given the above mentioned hypotheses for the origin of non-volatile mediators in $\mathrm{EBC}$, the composition may not reflect the true composition of sIL2R in the epithelial fluid at the level of the alveolus. As such measuring potential biomarkers in EBC may not be reliable in interstitial lung diseases. 
The clinical course and prognosis of sarcoidosis is extremely variable and no current guideline or gold standard is available to define disease activity. In our study all participants were symptomatic at the time of recruitment and were assessed within six months of diagnosis. Furthermore, with the exception of topical corticosteroid eye drops all participants were treatment naïve. This coupled with the short time lag between diagnosis and EBC sampling therefore ensured that patients were likely to have active disease at the time of recruitment that had not resolved spontaneously or following systemic immunosuppressive treatment.

As online EBC measurements are not available, prior to analysis, particularly using an immunoassay, EBC samples are often stored and then analysed in a batch to avoid interassay variability. The effects of long term storage on the stability of various mediators within EBC as well as the optimal time frame between collection and analysis remains unknown. No relationship has been identified between the concentration of cytokines and storage for up to twelve months at -80 degrees centigrade (47), however other mediators such as leukotrienes undergo significant degradation within a short time period of only three months (48). To our knowledge no previous research was available regarding stability of SIL2R in breath condensate, therefore in keeping with current recommendations (35) we sought to analyse samples as quickly as possible as a single batch using the same immunoassay kit to minimise inter-assay variability and the potential effects of sample degradation.

\section{Study limitations}

There are several limitations to this study. Firstly, as this was a pilot study no previous data specifically relating to sIL2R in EBC was available on which to base a formal sample size calculation. As such, given the small sample size, the current study may have been underpowered to detect a significant difference between patients and healthy controls. As there were only three individuals with sarcoidosis with values higher than the lower detection limit of the immunoassay, the comparison between EBC sIL2R and clinical markers is limited. The cross-sectional design of the study also does not allow us to draw firm conclusions as to the clinical significance of detectable sIL2R in EBC during or around the time of diagnosis. Elevated serum sIL2R has been shown to be a potential prognostic marker in predicting risk of disease progression in treatment naïve patients with sarcoidosis (29). It 
is therefore unclear if the three participants with detectable sIL2R are subsequently more likely to require treatment, carry a poorer prognosis with an increased risk of future relapse or fibrotic lung disease or represent the third of patients at risk of developing chronic disease. Thirdly, all participants recruited were Caucasian which limits the generalisability of our findings. Various studies have shown that racial differences impact upon the trajectory and disease severity of sarcoidosis with African American patients having a more severe disease compared to Caucasians (49) (50) with increased risk of relapse and extra-thoracic involvement (1). The effect of race and ethnicity on the presence or concentration of sIL2R in EBC can therefore not be ascertained as non-Caucasian populations with more severe disease may be associated with significantly elevated levels of EBC sIL2R compared to Caucasian patients with less severe disease and fewer extra-pulmonary manifestations. Although we recruited participants with a broad range of radiological stages, we were unable to recruit any participants with stage IV or fibrotic lung disease. However, despite four participants who were graded as stage 0 according to the Scadding radiological criteria, on computerised tomography scanning all participants had evidence of intrathoracic disease with the presence of at least hilar or mediastinal lymphadenopathy which would be indicative of stage I disease on the Scadding criteria. Furthermore, in patients with mediastinal and hilar lymphadenopathy, although pulmonary infiltrates may not be visible on imaging, parenchymal granulomas are frequently found in lung tissue biopsies indicating lung involvement. Finally we did not assess for salivary contamination and as previously mentioned, we did not perform analysis on lyophilised samples therefore dilution may have accounted for the inability to detect sIL2R in $75 \%$ of EBC samples collected from patients with sarcoidosis. Further research should therefore focus on the measurement of sIL2R using lyophilised EBC samples.

\section{Conclusion}

The results from this pilot study suggest that sIL2R is present and detectable in EBC in only $25 \%$ of people with sarcoidosis and in $16 \%$ of healthy controls measured using an immunoassay. When detectable the concentration of SIL2R was near the lower limit of detection of the assay we used. We could not determine a statistically significant difference between participants with sarcoidosis and healthy controls therefore the findings of this study suggest that SIL2R in EBC does not have a diagnostic role when investigating patients 
with suspected pulmonary sarcoidosis. We could not identify any significant or apparent association of sIL2R in EBC in participants with sarcoidosis according to radiological stage, pulmonary function tests or markers of disease activity. Although there has been growing interest in breath research for many years, only exhaled nitric oxide has successfully transitioned from research into clinical practice to aid the diagnosis and management of asthma (51) (52). This reflects the many potential limitations which arise within the field of breath research mainly due to lack of standardised practice relating to collection, storage and analysis of such samples. The findings of this current study therefore echo many of these potential issues, notably the need to develop more sensitive analytical techniques and platforms with the ability to identify and quantify biomarkers which may be present in only extremely dilute concentrations as well as characterisation of normal reference values for EBC. We caution against further studies which attempt to measure biochemical markers in EBC using assays which rely on detection near the lower limit of normal. Whilst it appears that EBC SIL2R has no diagnostic potential in sarcoidosis, further research may be required to evaluate its prognostic role.

\section{Funding}

Funding for this study was provided by research funds within the Respiratory Medicine Department at the Norfolk and Norwich University Hospital NHS Foundation Trust. The research is being undertaken as part of a PhD programme (DLT).

\section{Acknowledgements}

The authors would like to personally thank Mrs Sue Robinson for her time and contribution towards this research. Stephen Fowler is supported by the NIHR Manchester Biomedical Research Centre.

\section{Declaration of Interest}

None declared. 
Table 1: Baseline study characteristics. Data expressed as mean and standard deviation unless otherwise stated. No significant difference was observed in clinical characteristics between participants with sarcoidosis and healthy controls ( $p$-value $>0.05$ ). MRC, Medical Research Council dyspnoea score; FEV1, forced expiratory volume in one second; FVC, forced vital capacity; TLCO, transfer factor of the lung for carbon monoxide; ACE, angiotensin converting enzyme; N/a, not applicable. * Chest radiograph was not available for one participant. **Two participants were treated with angiotensin converting enzyme inhibitors at the time of enrolment and had serum ACE $<12 \mathrm{U} / \mathrm{L} .{ }^{+}$Radiological staging based upon the Scadding criteria. 


\begin{tabular}{|c|c|c|c|}
\hline & $\begin{array}{l}\text { Sarcoidosis } \\
\qquad(n=12)\end{array}$ & $\begin{array}{l}\text { Healthy controls } \\
\qquad(n=12)\end{array}$ & P-value \\
\hline Age (years) & $53.0 \pm 16.2$ & $51.7 \pm 15.3$ & 0.83 \\
\hline Male/female (n) & $7 / 5$ & $7 / 5$ & \\
\hline $\begin{array}{l}\text { Radiological stage } \\
(0 / \mathrm{I} / \mathrm{II} / \mathrm{III} / \mathrm{IV})^{+}\end{array}$ & $(4 / 3 / 2 / 2 / 0)^{*}$ & $\mathrm{~N} / \mathrm{a}$ & \\
\hline $\begin{array}{l}\text { Smoking status } \\
\text { (previous/never) }\end{array}$ & $8 / 4$ & $3 / 9$ & \\
\hline Smoking pack years & $2.21 \pm 2.09$ & $0.75 \pm 1.67$ & 0.07 \\
\hline $\begin{array}{l}\text { Duration from diagnosis to } \\
\text { sampling (days) }\end{array}$ & $84.58 \pm 48.17$ & $\mathrm{~N} / \mathrm{a}$ & \\
\hline $\begin{array}{l}\text { Extra-pulmonary } \\
\text { manifestations }\end{array}$ & $\begin{array}{l}\text { Current uveitis }(n=1) \\
\text { Fatigue }(n=7) \\
\text { Arthralgia }(n=6) \\
\text { Hepatic sarcoidosis ( } n= \\
1 \text { ) } \\
\text { Previous uveitis }(n=2) \\
\text { Previous erythema } \\
\text { nodosum }(n=1)\end{array}$ & $\mathrm{N} / \mathrm{a}$ & \\
\hline MRC dyspnoea score & $1.42 \pm 0.52$ & $\mathrm{~N} / \mathrm{a}$ & \\
\hline $\begin{array}{l}\text { Previous systemic } \\
\text { immunosuppressive } \\
\text { treatment (yes/no) }\end{array}$ & $0 / 12$ & $\mathrm{~N} / \mathrm{a}$ & \\
\hline $\begin{array}{l}\text { Family history of sarcoidosis } \\
\text { (yes/no) }\end{array}$ & $0 / 12$ & $0 / 12$ & \\
\hline FEV1 (L) & $3.03 \pm 0.75$ & $3.34 \pm 0.85$ & 0.70 \\
\hline FEV1 (\% predicted) & $98.31 \pm 11.83$ & $102.88 \pm 17.01$ & 0.27 \\
\hline FVC (L) & $3.95 \pm 0.65$ & $4.44 \pm 1.21$ & 0.18 \\
\hline FVC (\% predicted) & $107.74 \pm 14.17$ & $110.58 \pm 13.24$ & 0.97 \\
\hline FEV1/FVC ratio & $76.13 \pm 8.49$ & $75.94 \pm 6.67$ & \\
\hline Total lung capacity (L) & $6.42 \pm 0.81$ & $\mathrm{~N} / \mathrm{a}$ & \\
\hline $\begin{array}{l}\text { Total lung capacity (\% } \\
\text { predicted) }\end{array}$ & $104.64 \pm 11.05$ & $\mathrm{~N} / \mathrm{a}$ & \\
\hline TLCO $\left(\mathrm{mmol} \mathrm{min}^{-1} \mathrm{kPa}^{-1}\right)$ & $8.05 \pm 1.85$ & $\mathrm{~N} / \mathrm{a}$ & \\
\hline TLCO (\% predicted) & $87.91 \pm 17.76$ & $\mathrm{~N} / \mathrm{a}$ & \\
\hline $\begin{array}{l}\text { Peripheral lymphocyte } \\
\text { count }\left(10^{9} / \mathrm{L}\right)\end{array}$ & $1.19 \pm 0.48$ & $\mathrm{~N} / \mathrm{a}$ & \\
\hline Serum calcium (mmol/L) & $2.39 \pm 0.09$ & $\mathrm{~N} / \mathrm{a}$ & \\
\hline $\begin{array}{l}\text { Serum calcium (adjusted) } \\
\text { (mmol/L) }\end{array}$ & $2.42 \pm 0.09$ & $\mathrm{~N} / \mathrm{a}$ & \\
\hline $\begin{array}{l}\text { Erythrocyte sedimentation } \\
\text { rate }(\mathrm{mm} / \mathrm{h})\end{array}$ & $10.42 \pm 8.10$ & $\mathrm{~N} / \mathrm{a}$ & \\
\hline C-reactive protein (mg/L) & $4.88 \pm 7.40$ & $\mathrm{~N} / \mathrm{a}$ & \\
\hline
\end{tabular}


Elevated serum ACE (yes/no) (U/L)
$4 / 8^{* *}$

$62.90 \pm 23.78$

$\mathrm{N} / \mathrm{a}$

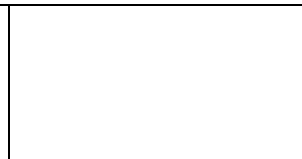


Table 2: Individual key clinical characteristics for all twelve participants with sarcoidosis. MRC, Medical Research Council dyspnoea score; FEV1, forced expiratory volume in one second; FVC, forced vital capacity; TLCO, transfer factor of the lung for carbon monoxide; PFTs, pulmonary function tests; ESR, erythrocyte sedimentation rate; $A C E$, angiotensin converting enzyme; eGFR, estimated glomerular filtration rate; EBC exhaled breath condensate; sIL2R, soluble interleukin-2 receptor; A, self reported arthralgia; HS, hepatic sarcoidosis; $F$, fatigue; O, self reported ocular symptoms with no formal diagnosis of uveitis; $C U$, current uveitis receiving topical corticosteroid eye drops; $\mathrm{PU}$, previous uveitis; PEN, previous erythema nodosum. *Result above the upper normal reference range for the reporting laboratory or two standard deviations above the manufacturers referenced mean value for healthy controls. **Result below the lower normal reference range for the reporting laboratory. ${ }^{\dagger}$ Receiving treatment with an angiotensin converting enzyme inhibitor at the time of recruitment. ${ }^{+\dagger}$ Not detectable, therefore arbitrary value of half the lower limit of detection assigned.

\begin{tabular}{|c|c|c|c|c|c|c|c|c|c|c|c|c|}
\hline & I & II & III & IV & $\mathbf{v}$ & VI & VII & VIII & IX & $x$ & $\mathbf{X I}$ & XII \\
\hline Age (years) & 76 & 66 & 27 & 38 & 56 & 77 & 44 & 30 & 58 & 49 & 60 & 55 \\
\hline Gender & Male & Female & Male & Female & Female & Female & Male & Male & Male & Female & Male & Male \\
\hline Radiological stage & 1 & 3 & 1 & 0 & 3 & 0 & 0 & $\begin{array}{l}\text { No chest } \\
\text { radiograph }\end{array}$ & 0 & 1 & 2 & 2 \\
\hline $\begin{array}{l}\text { Extra-pulmonary } \\
\text { manifestations }\end{array}$ & $\begin{array}{l}\text { None } \\
\text { reported }\end{array}$ & $\begin{array}{l}\text { None } \\
\text { reported }\end{array}$ & A & A & $\begin{array}{c}\text { A, F, O, } \\
\text { HS }\end{array}$ & $\begin{array}{c}A, F, C U \\
P U\end{array}$ & $\mathrm{~F}, \mathrm{O}$ & $\mathrm{F}$ & $A$ & $\begin{array}{l}\text { A, F, O, } \\
\text { PU, PEN }\end{array}$ & $\mathrm{F}, \mathrm{O}$ & $\mathrm{F}$ \\
\hline MRC dyspnoea score & 1 & 2 & 2 & 1 & 2 & 1 & 1 & 2 & 1 & 2 & 1 & 1 \\
\hline $\begin{array}{l}\text { FEV1 (L)/FEV1 (\% } \\
\text { predicted) }\end{array}$ & $2.37 / 98$ & $2.62 / 104$ & $4.74 / 108$ & $2.96 / 104$ & $2.30 / 88$ & $2.13 / 115$ & $3.31 / 93$ & $3.47 / 80$ & $3.66 / 111$ & $2.34 / 83$ & $3.41 / 109$ & $3.12 / 87$ \\
\hline $\begin{array}{l}\mathrm{FVC}(\mathrm{L}) / \mathrm{FVC}(\% \\
\text { predicted) }\end{array}$ & $3.20 / 110$ & $3.35 / 113$ & $5.35 / 103$ & $3.70 / 112$ & $3.68 / 121$ & $3.10 / 137$ & $3.82 / 88$ & $4.29 / 83$ & $4.34 / 104$ & $3.58 / 109$ & $4.45 / 113$ & $4.5 / 100$ \\
\hline
\end{tabular}




\begin{tabular}{|c|c|c|c|c|c|c|c|c|c|c|c|c|}
\hline $\begin{array}{l}\text { TLCO (mmol min }{ }^{-1} \\
\left.\mathrm{kPa}^{-1}\right) / \mathrm{TLCO}(\% \\
\text { predicted) }\end{array}$ & $9.23 / 117$ & $5.69 / 71$ & $11.1 / 93$ & $\begin{array}{c}\text { Full PFTs } \\
\text { unavailable }\end{array}$ & $5.92 / 72$ & $6.93 / 104$ & $8.76 / 88$ & $8.47 / 72$ & $10.64 / 115$ & $5.90 / 68$ & $8.01 / 89$ & $7.93 / 78$ \\
\hline $\begin{array}{l}\text { Peripheral } \\
\text { lymphocyte count } \\
\left(10^{9} / \mathrm{L}\right)\end{array}$ & $0.78 * *$ & 1.29 & $0.71 * *$ & 1.77 & 2.18 & $0.95 * *$ & 1.72 & 1.01 & $0.86 * *$ & 1.01 & $0.64 * *$ & 1.11 \\
\hline $\begin{array}{l}\text { Serum calcium } \\
\text { (adjusted) (mmol/L) }\end{array}$ & 2.55 & 2.27 & 2.38 & 2.27 & 2.41 & 2.37 & 2.49 & 2.52 & 2.39 & 2.40 & 2.45 & 2.57 \\
\hline $\mathrm{ESR}(\mathrm{mm} / \mathrm{h})$ & 16 & 5 & 5 & 2 & 8 & 5 & 27 & 2 & 5 & 16 & 21 & 13 \\
\hline Serum ACE & 61 & $93^{*}$ & $73^{*}$ & 44 & 48 & $<12^{* *}$ & 31 & 38 & $<12^{* * \dagger}$ & 56 & $98^{*}$ & $87 *$ \\
\hline $\begin{array}{l}\text { eGFR } \\
\left(\mathrm{mL} / \mathrm{min} / 1.73 \mathrm{~m}^{2}\right)\end{array}$ & 79 & $>90$ & $>90$ & $>90$ & $>90$ & 42 & $>90$ & 86 & $>90$ & 88 & 88 & 89 \\
\hline EBC slL2R (pg/mL) & $5.0^{+\dagger}$ & $5.0^{+\dagger}$ & 285.8 & $5.0^{\dagger+}$ & $5.0^{+\dagger}$ & $5.0^{+\dagger}$ & $5.0^{+\dagger}$ & 288.2 & 148.0 & $5.0^{+\dagger}$ & $5.0^{+\dagger}$ & $5.0^{+\dagger}$ \\
\hline Serum sIL2R (pg/mL) & $2689.6^{*}$ & 1458.9 & 1240.4 & 1423.4 & 767.5 & $1926.3^{*}$ & 1309.7 & 1688.4 & 1119.0 & 1659.8 & $1868.5^{*}$ & $1860.0^{*}$ \\
\hline
\end{tabular}


Table 3: Comparison between the Scadding criteria and radiological manifestations evident on computerised tomography cross-sectional imaging of the thorax.

\begin{tabular}{|c|c|c|}
\hline Subject & $\begin{array}{l}\text { Scadding } \\
\text { Stage }\end{array}$ & Cross-sectional Thoracic Imaging Findings \\
\hline 1 & 1 & Mediastinal and hilar lymphadenopathy with possible calcification. \\
\hline$\|$ & 3 & $\begin{array}{l}\text { Multiple unenlarged part calcified mediastinal and hilar lymph } \\
\text { nodes. Peribronchovascular nodularity in the mid and upper zones. }\end{array}$ \\
\hline III & 1 & $\begin{array}{l}\text { Bilateral mediastinal and hilar lymphadenopathy. } \\
5 \mathrm{~mm} \text { subpleural middle lobe, } 8 \mathrm{~mm} \text { right lower lobe, } 4 \mathrm{~mm} \text { left lower } \\
\text { lobe and } 4 \mathrm{~mm} \text { left upper lobe nodules. }\end{array}$ \\
\hline IV & 0 & Symmetrical and bilateral mediastinal and hilar lymphadenopathy. \\
\hline V & 3 & $\begin{array}{l}\text { Mediastinal and hilar lymphadenopathy. } \\
\text { Extensive nodularity with perifissural nodularity. }\end{array}$ \\
\hline $\mathrm{VI}$ & 0 & Left sided mediastinal and hilar lymphadenopathy. \\
\hline VII & 0 & $\begin{array}{l}\text { Right hilar and paratracheal lymphadenopathy. } \\
\text { Multiple nodules measuring up to } 8 \mathrm{~mm} \text { in the right lower lobe. }\end{array}$ \\
\hline VIII & $\begin{array}{l}\text { No chest } \\
\text { radiograph }\end{array}$ & $\begin{array}{l}\text { Bilateral mediastinal and hilar lymphadenopathy. } \\
7 \mathrm{~mm} \text { left lower lobe nodule. }\end{array}$ \\
\hline IX & 0 & $\begin{array}{l}\text { Mediastinal and hilar lymphadenopathy. } \\
\text { Scattered } 5 \mathrm{~mm} \text { nodules in the right upper lobe. }\end{array}$ \\
\hline $\mathrm{x}$ & 1 & $\begin{array}{l}\text { Mediastinal and hilar lymphadenopathy. } \\
\text { Reticulonodular shadowing in the right mid to upper zones and left } \\
\text { upper zone. }\end{array}$ \\
\hline$X I$ & 2 & $\begin{array}{l}\text { Mediastinal and hilar lymphadenopathy. } \\
\text { Widespread centrilobular and peribronchovascular nodules and } \\
\text { perifissural nodularity. }\end{array}$ \\
\hline $\mathrm{XII}$ & 2 & $\begin{array}{l}\text { Symmetrical and bilateral mediastinal and hilar lymphadenopathy. } \\
\text { Bilateral subpleural and perifissural nodularity, } 6 \mathrm{~mm} \text { left upper } \\
\text { lobe, } 9 \mathrm{~mm} \text { right upper lobe, } 4 \mathrm{~mm} \text { and } 5 \mathrm{~mm} \text { left lower lobe nodules. }\end{array}$ \\
\hline
\end{tabular}




\section{References}

1. Costabel U, Hunninghake GW. ATS/ERS/WASOG statement on sarcoidosis. Sarcoidosis Statement Committee. American Thoracic Society. European Respiratory Society. World Association for Sarcoidosis and Other Granulomatous Disorders. The European respiratory journal. 1999;14(4):735-7.

2. Iannuzzi MC, Rybicki BA, Teirstein AS. Sarcoidosis. The New England journal of medicine. 2007;357(21):2153-65.

3. Valeyre D, Prasse A, Nunes H, Uzunhan Y, Brillet PY, Muller-Quernheim J. Sarcoidosis. Lancet (London, England). 2014;383(9923):1155-67.

4. Ahmadzai H, Sheng Joshua Loke W, Huang S, Herbert C, Wakefield D, S. Thomas P. Biomarkers in sarcoidosis: a review2014. 93-106 p.

5. Bennett D, Cameli P, Lanzarone N, Carobene L, Bianchi N, Fui A, et al. Chitotriosidase: a biomarker of activity and severity in patients with sarcoidosis. Respiratory research. 2020;21(1):6.

6. Bargagli E, Bennett D, Maggiorelli C, Di Sipio P, Margollicci M, Bianchi N, et al. Human chitotriosidase: a sensitive biomarker of sarcoidosis. Journal of clinical immunology. 2013;33(1):26470.

7. Kharitonov SA, Barnes PJ. Exhaled markers of pulmonary disease. American journal of respiratory and critical care medicine. 2001;163(7):1693-722.

8. Horvath I, Hunt J, Barnes PJ, Alving K, Antczak A, Baraldi E, et al. Exhaled breath condensate: methodological recommendations and unresolved questions. The European respiratory journal. 2005;26(3):523-48.

9. Rosias P. Methodological aspects of exhaled breath condensate collection and analysis. Journal of breath research. 2012;6(2):027102.

10. Johnson GR, Morawska L. The mechanism of breath aerosol formation. Journal of aerosol medicine and pulmonary drug delivery. 2009;22(3):229-37.

11. Kwiatkowska S, Luczynska M, Grzelewska-Rzymowska I, Nowak D, Zieba M. [Comparison of oxidative stress markers in exhaled breath condensate and in serum of patients with tuberculosis and sarcoidosis]. Polski merkuriusz lekarski : organ Polskiego Towarzystwa Lekarskiego. 2005;19(109):37-40.

12. Psathakis K, Papatheodorou G, Plataki M, Panagou P, Loukides S, Siafakas NM, et al. 8Isoprostane, a marker of oxidative stress, is increased in the expired breath condensate of patients with pulmonary sarcoidosis. Chest. 2004;125(3):1005-11.

13. Piotrowski WJ, Kurmanowska Z, Antczak A, Marczak J, Gorski P. Exhaled 8-isoprostane as a prognostic marker in sarcoidosis. A short term follow-up: BMC Pulmonary Medicine. 10 (no pagination), 2010. Article Number: 23. Date of Publication: 27 Apr 2010.

14. Ahmadzai H, Cameron B, Chui J, Lloyd A, Wakefield D, Thomas PS. Measurement of neopterin, TGF-beta1 and ACE in the exhaled breath condensate of patients with sarcoidosis. Journal of breath research. 2013;7(4):046003.

15. Mohan N, Akter R, Bryant K, Herbert C, Chow S, Thomas P. Exhaled breath markers of alveolar macrophage activity in sarcoidosis. Inflammation Research. 2016;65(6):471-8.

16. Piotrowski WJ, Antczak A, Marczak J, Nawrocka A, Kurmanowska Z, Gorski P. Eicosanoids in exhaled breath condensate and BAL fluid of patients with sarcoidosis. Chest. 2007;132(2):589-96.

17. Terrington D, Hayton C, Peel AM, Fowler SJ, Fraser W, Wilson AM. The role of measuring exhaled breath biomarkers in sarcoidosis: A systematic review. Journal of breath research. 2019.

18. Eurelings LEM, Miedema JR, Dalm V, van Daele PLA, van Hagen PM, van Laar JAM, et al. Sensitivity and specificity of serum soluble interleukin-2 receptor for diagnosing sarcoidosis in a population of patients suspected of sarcoidosis. PloS one. 2019;14(10):e0223897. 
19. Rubin LA, Kurman CC, Fritz ME, Biddison WE, Boutin B, Yarchoan R, et al. Soluble interleukin 2 receptors are released from activated human lymphoid cells in vitro. Journal of immunology (Baltimore, Md : 1950). 1985;135(5):3172-7.

20. Semenzato G, Cipriani A, Trentin L, Zambello R, Masciarelli M, Vinante F, et al. High serum levels of soluble interleukin-2 receptors in sarcoidosis. Sarcoidosis. 1987;4(1):25-7.

21. Ina Y, Takada K, Noda M, Satou T, Hashiba H, Miyachi A, et al. [Serum soluble IL-2 receptor level in patients with sarcoidosis]. Nihon Kyobu Shikkan Gakkai zasshi. 1991;29(3):316-21.

22. Lawrence EC, Brousseau KP, Berger MB, Kurman CC, Marcon L, Nelson DL. Elevated concentrations of soluble interleukin-2 receptors in serum samples and bronchoalveolar lavage fluids in active sarcoidosis. The American review of respiratory disease. 1988;137(4):759-64.

23. Petereit HF, Reske D, Tumani H, Jarius S, Markus Leweke F, Woitalla D, et al. Soluble CSF interleukin 2 receptor as indicator of neurosarcoidosis. Journal of neurology. 2010;257(11):1855-63.

24. Tsutsumi T, Nagai S, Imai K, Setoyama Y, Uchiyama T, Izumi T. Soluble interleukin-2 receptor in blood from patients with sarcoidosis and idiopathic pulmonary fibrosis. Sarcoidosis. 1994;11(2):102-9.

25. Lawrence EC, Berger MB, Brousseau KP, Rodriguez TM, Siegel SJ, Kurman CC, et al. Elevated serum levels of soluble interleukin-2 receptors in active pulmonary sarcoidosis: relative specificity and association with hypercalcemia. Sarcoidosis. 1987;4(2):87-93.

26. Keicho N, Kitamura K, Takaku F, Yotsumoto H. Serum concentration of soluble interleukin-2 receptor as a sensitive parameter of disease activity in sarcoidosis. Chest. 1990;98(5):1125-9.

27. Uysal P, Durmus S, Sozer V, Gelisgen R, Seyhan EC, Erdenen F, et al. YKL-40, Soluble IL-2 Receptor, Angiotensin Converting Enzyme and C-Reactive Protein: Comparison of Markers of Sarcoidosis Activity. Biomolecules. 2018;8(3).

28. Ziegenhagen MW, Rothe ME, Schlaak M, Muller-Quernheim J. Bronchoalveolar and serological parameters reflecting the severity of sarcoidosis. The European respiratory journal. 2003;21(3):407-13.

29. Ziegenhagen MW, Benner UK, Zissel G, Zabel P, Schlaak M, Muller-Quernheim J. Sarcoidosis: TNF-alpha release from alveolar macrophages and serum level of sIL-2R are prognostic markers. American journal of respiratory and critical care medicine. 1997;156(5):1586-92.

30. Miyoshi S, Hamada H, Kadowaki T, Hamaguchi N, Ito R, Irifune K, et al. Comparative evaluation of serum markers in pulmonary sarcoidosis. Chest. 2010;137(6):1391-7.

31. Thi Hong Nguyen C, Kambe N, Kishimoto I, Ueda-Hayakawa I, Okamoto H. Serum soluble interleukin-2 receptor level is more sensitive than angiotensin-converting enzyme or lysozyme for diagnosis of sarcoidosis and may be a marker of multiple organ involvement. The Journal of dermatology. 2017;44(7):789-97.

32. Gungor S, Ozseker F, Yalcinsoy M, Akkaya E, Can G, Eroglu H, et al. Conventional markers in determination of activity of sarcoidosis. International immunopharmacology. 2015;25(1):174-9.

33. Vorselaars AD, van Moorsel CH, Zanen P, Ruven HJ, Claessen AM, van Velzen-Blad $H$, et al. $A C E$ and sIL-2R correlate with lung function improvement in sarcoidosis during methotrexate therapy. Respiratory medicine. 2015;109(2):279-85.

34. Scheideler L, Manke HG, Schwulera U, Inacker O, Hammerle H. Detection of nonvolatile macromolecules in breath. A possible diagnostic tool? The American review of respiratory disease. 1993;148(3):778-84.

35. Horvath I, Barnes PJ, Loukides S, Sterk PJ, Hogman M, Olin AC, et al. A European Respiratory Society technical standard: exhaled biomarkers in lung disease. The European respiratory journal. 2017;49(4).

36. Miller MR, Hankinson J, Brusasco V, Burgos F, Casaburi R, Coates A, et al. Standardisation of spirometry. The European respiratory journal. 2005;26(2):319-38.

37. Wanger J, Clausen JL, Coates A, Pedersen OF, Brusasco V, Burgos F, et al. Standardisation of the measurement of lung volumes. The European respiratory journal. 2005;26(3):511-22. 
38. Macintyre N, Crapo RO, Viegi G, Johnson DC, van der Grinten CP, Brusasco V, et al. Standardisation of the single-breath determination of carbon monoxide uptake in the lung. The European respiratory journal. 2005;26(4):720-35.

39. Scadding JG. Prognosis of intrathoracic sarcoidosis in England. A review of 136 cases after five years' observation. British medical journal. 1961;2(5261):1165-72.

40. Effros RM, Hoagland KW, Bosbous M, Castillo D, Foss B, Dunning $M$, et al. Dilution of respiratory solutes in exhaled condensates. American journal of respiratory and critical care medicine. 2002;165(5):663-9.

41. Cepelak I, Dodig S. Exhaled breath condensate: a new method for lung disease diagnosis. Clinical chemistry and laboratory medicine. 2007;45(8):945-52.

42. Syslova K, Kacer P, Kuzma M, Pankracova A, Fenclova Z, Vlckova S, et al. LC-ESI-MS/MS method for oxidative stress multimarker screening in the exhaled breath condensate of asbestosis/silicosis patients. Journal of breath research. 2010;4(1):017104.

43. Lacombe M, Marie-Desvergne $C$, Combes $F$, Kraut A, Bruley C, Vandenbrouck $Y$, et al. Proteomic characterization of human exhaled breath condensate. Journal of breath research. 2018;12(2):021001.

44. Fernandez-Peralbo MA, Calderon Santiago M, Priego-Capote F, Luque de Castro MD. Study of exhaled breath condensate sample preparation for metabolomics analysis by LC-MS/MS in high resolution mode. Talanta. 2015;144:1360-9.

45. Debley JS, Hallstrand TS, Monge T, Ohanian A, Redding GJ, Zimmerman J. Methods to improve measurement of cysteinyl leukotrienes in exhaled breath condensate from subjects with asthma and healthy controls. The Journal of allergy and clinical immunology. 2007;120(5):1216-7.

46. Tishler M, Yaron I, Shirazi I, Levartovsky D, Yaron M. Salivary and serum soluble interleukin-2 receptor in primary Sjögren's syndrome. Arch Oral Biol. 1999;44(4):305-8.

47. Robroeks CM, van de Kant KD, Jobsis $Q$, Hendriks HJ, van Gent R, Wouters EF, et al. Exhaled nitric oxide and biomarkers in exhaled breath condensate indicate the presence, severity and control of childhood asthma. Clinical and experimental allergy : journal of the British Society for Allergy and Clinical Immunology. 2007;37(9):1303-11.

48. Ohanian AS, Zimmerman J, Debley JS. Effects of sample processing, time and storage condition on cysteinyl leukotrienes in exhaled breath condensate. Journal of breath research. 2010;4(4):046002.

49. Rabin DL, Thompson B, Brown KM, Judson MA, Huang X, Lackland DT, et al. Sarcoidosis: social predictors of severity at presentation. The European respiratory journal. 2004;24(4):601-8.

50. Baughman RP, Nagai S, Balter M, Costabel U, Drent M, du Bois R, et al. Defining the clinical outcome status (COS) in sarcoidosis: results of WASOG Task Force. Sarcoidosis, vasculitis, and diffuse lung diseases : official journal of WASOG. 2011;28(1):56-64.

51. Dweik RA, Boggs PB, Erzurum SC, Irvin CG, Leigh MW, Lundberg JO, et al. An official ATS clinical practice guideline: interpretation of exhaled nitric oxide levels (FENO) for clinical applications. American journal of respiratory and critical care medicine. 2011;184(5):602-15.

52. ATS/ERS recommendations for standardized procedures for the online and offline measurement of exhaled lower respiratory nitric oxide and nasal nitric oxide, 2005. American journal of respiratory and critical care medicine. 2005;171(8):912-30. 